\title{
REPRODUCIBILITY STUDY OF POSTERIOR SUBCAPSULAR OPACITIES ON THE NEI RETROILLUMINATION IMAGE ANALYSIS SYSTEM
}

\author{
MARIA LOUELLA L. LOPEZ ${ }^{1}$, MANUEL B. DATILES III' ${ }^{1}$ MARVIN J. PODGOR ${ }^{2}$, \\ MARK A. VIVINO ${ }^{3}$, ANUP A. MAHURKAR ${ }^{1}$ and SUSAN M. LASA ${ }^{1}$ \\ Bethesda, Maryland, USA
}

\begin{abstract}
SUMMARY
We developed a semi-automated retroillumination image analysis system which combines speed, ease of operation and interactive analysis. The system measures cataract area and integral of cataract density (ID). For system reproducibility evaluation, 20 eyes with posterior subcapsular opacities were captured twice by two photographers. Variability was estimated under a random effects analysis of variance model. Measurement errors for area and for ID were each small contributors to total variability (the sum of variability between study eyes plus measurement error), being $0.4 \%$ and $0.1 \%$ respectively. The largest contributor to area measurement error was image analysis variability $(97 \%)$. For ID measurement error, the variability in images $(44 \%)$ and in image analysis $(46 \%)$ were major contributors. The reproducibility is comparable to previously described retroillumination analysis systems. This easy to use system may therefore be useful in clinical research studies including possible clinical trials of anti-cataract drugs.
\end{abstract}

Retroillumination photography has proved to be a valuable tool for in vivo documentation of the characteristics of cortical and posterior subcapsular cataracts. Current techniques of retroillumination photography are based on the method described by Fincham' in 1955 wherein the illuminating and observing axes are made to coincide by a $45^{\circ}$ glass plate. Technical improvements have recently been made with the retroillumination image quality. Kawara and Obazawa ${ }^{2}$ introduced crossed polarising filters

From: 'Section on Cataract and Cornea, Ophthalmic Genetics and Clinical Services Branch, 'Division of Biometry and Epidemiology, National Eye Institute, and ${ }^{3}$ Computational Bioscience and Engineering Laboratory, Division of Computer Research and Technology, National Institutes of Health, Bethesda, Maryland, USA.

Correspondence to: Manuel B. Datiles III, MD, National Eye Institute, National Institutes of Health, Building 10, Room 10N226, 9000 Rockville Pike, Bethesda, MD 20892, USA. Fax: (301 402-1214. that minimised unwanted corneal light reflexes. Brown ${ }^{3-5}$ added fixation lights to tackle the image alignment problem, incorporated a CCD (charged-coupled device) camera to give a digital picture output and introduced a blocking device in the illumination pathway to exclude the remaining corneal reflection. These developments have led to better reproducibility of the retroillumination images and in turn have allowed the application of quantitative image analysis techniques.

Several automated and semi-automated methods of cataract quantification from retroillumination images have been devised..$^{4-6-12}$ These methods are of great importance to lens research as they measure cataract severity and/or progression and could be used in natural history, anticataract drug evaluation and toxicity studies. Nearly all of them assess cataract severity in terms of cataract area or size. Some have measured a type of density function.

Recently the National Eye Institute (NEI) designed a new retroillumination image analysis system. It is a userfriendly, semi-automated system offering new measures for quantifying the extent of cataract pathology. The system measures the total and percentage area of opacity, computes the net integral of density, centrality of the area and density, and centrality-weighted values of area and density. In this study we evaluated the reproducibility of two cataract measurements (area and net integral of density) obtained by the system.

\section{MATERIALS AND METHODS}

Image Analysis System ${ }^{13}$

Retroillumination images were acquired with the Oxford retroillumination CCD camera system (Marcher Enterprises, Hereford, UK). The procedure for taking the images was automated and required little input other than aligning the camera until a sharply focused image of the opacity was obtained. The acquired retroillumination 
Table I. Criteria for good exposure quality of retroillumination images

\begin{tabular}{lc}
\hline Histogram characteristics of image & Grey level units \\
\hline Mean $(\mu)$ & $65 \leqslant \mu_{\mathrm{GL}} \leqslant 190$ \\
Image upper boundary $\left(\mathrm{UB}_{\mathrm{GL}}\right)$ & $105 \leqslant \mu_{\mathrm{GL}} \leqslant 250$ \\
Image lower boundary $\left(\mathrm{LB}_{\mathrm{GL}}\right)$ & $5 \leqslant \mu_{\mathrm{GL}} \leqslant 150$ \\
Range & $\leqslant 220$ \\
$\mu+2 \mathrm{SD}$ & $\leqslant 30$ \\
$\mu-2 \mathrm{SD}$ & $\leqslant$ \\
\hline
\end{tabular}

images were then transferred from the host PC to a Macintosh Quadra 700 computer. Images were deemed acceptable in quality if they passed histogram-based tests for exposure quality (Fig. 1). The basic criteria used for testing the quality of an image for proper exposure are shown in Table I. In essence these are that the image should not be over- or underexposed, should contain reasonably good contrast and should not have severe gradients in the background illumination level. Depending on the results of the exposure tests, the CCD camera gain setting can be adjusted accordingly prior to repeating the image acquisition procedure.

Analysis of the retroillumination images was performed using a modified version of the Macintosh-based NIH Image program. ${ }^{14}$ This software first corrects for the varying background illumination of each image and then dichotomises the image into cataractous and non-catar- actous segments. A two-dimensional rolling-ball background subtraction routine ${ }^{15}$ is employed to correct the image for uneven background illumination (Fig. 2A). Once the background level of the image is made uniform, a polynomial function is used to determine the threshold grey level that identifies the cataractous area in the image. Data are converted to the optical density scale, with the optical density $(O D)$ of any pixel $(i j)$ being calculated from the logarithmic ratio of the grey level of the unmodified image and that of the background level found by the background subtraction routine:

$$
\text { Calculated } O D[i, j]=\left(\frac{\text { pixel grey level }[i, j]}{\text { background grey level }[i, j]}\right)
$$

At this point, the analyser is allowed to edit the image manually for artefacts and isolated non-cataractous agerelated lens changes. These age-related lens changes include retrodots, vacuoles, small lamellar separations, axial and peripheral dot opacities, sutural opacities and water clefts. Seven cataract indices are subsequently measured: area, percentage area of cataract, net integral of cataract density, centrality of the area and density, and centrality-weighted values of area and density. In this study we limited ourselves to area and density (Fig. 2B), since centrality and centrality-weighted measures impart little additional information in the evaluation of centrally

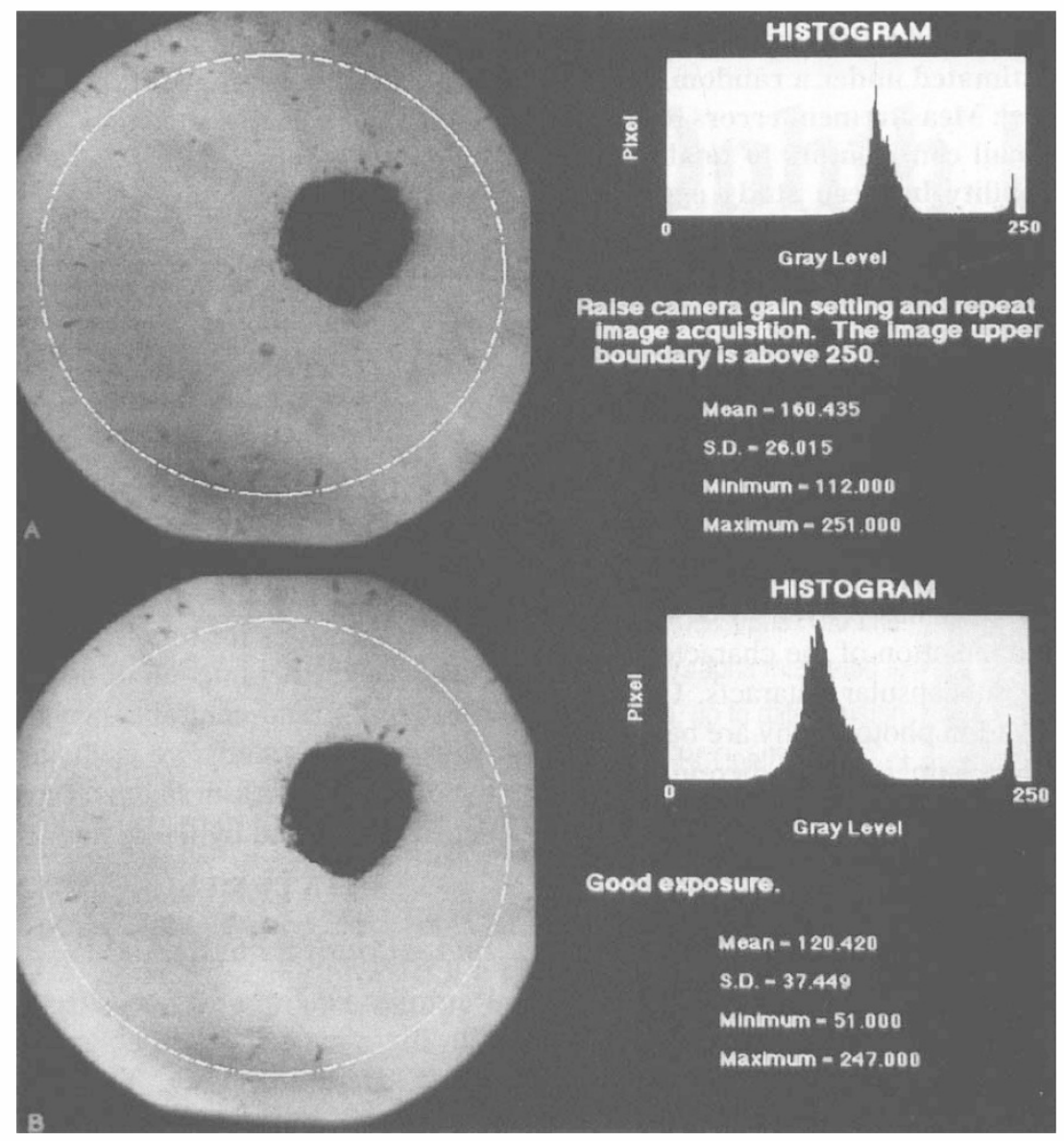

Fig. 1. Examples of histogram-based tests for exposure quality done on two retroillumination images of a posterior subcapsular cataract. The two images were done at different CCD camera gain settings. Note that the histogram characteristics are different for the two images despite their similar appearance. 

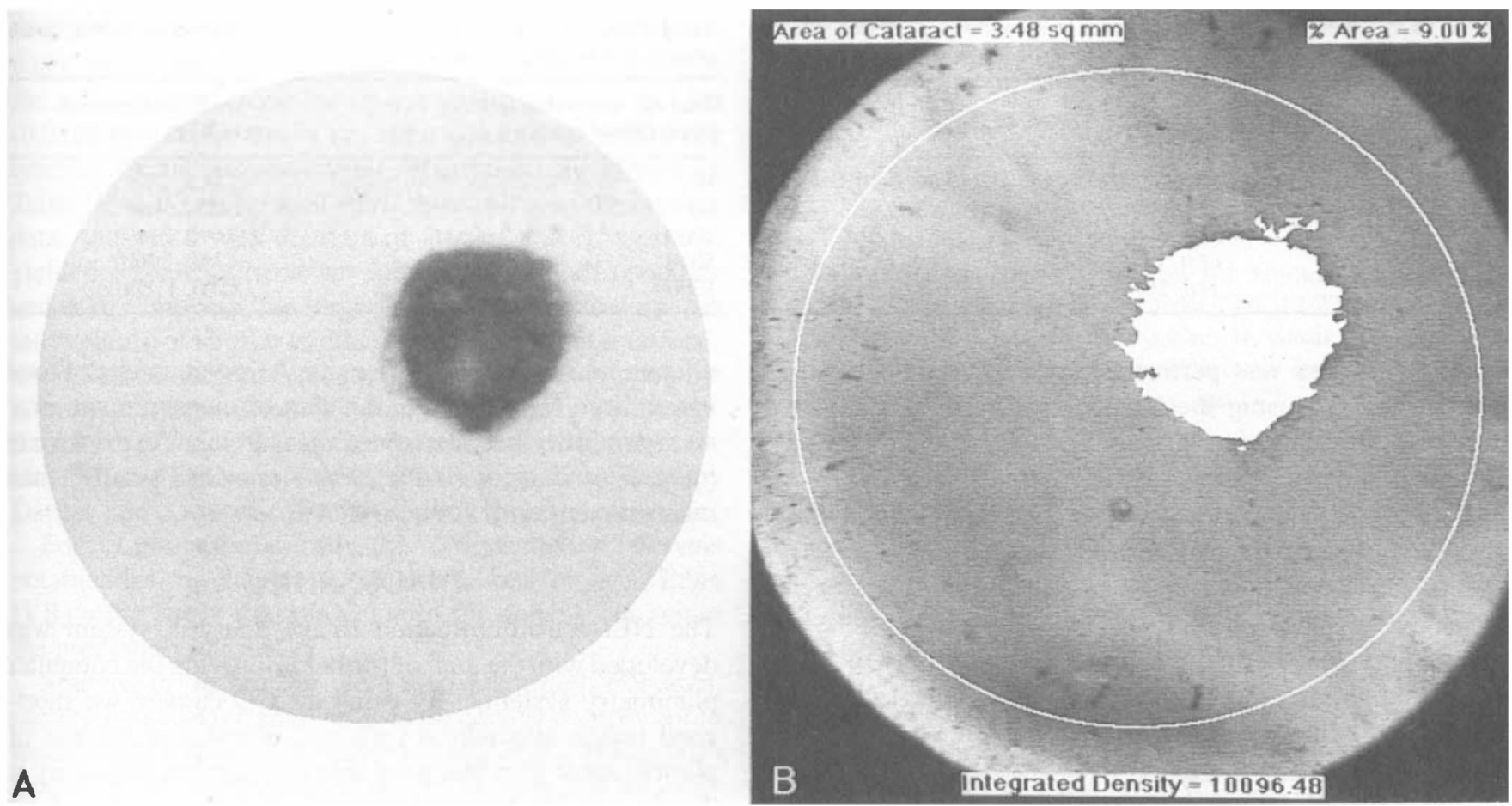

Fig. 2. The same retroillumination image as in Fig. 1 B after correction for the uneven background illumination (A), and after analysis (B). Computed area (square millimetres), percentage area of cataract and net integral of cataract density are shown.

located posterior subcapsular opacities. The net integral of cataract density $(I D)$ is computed as the sum of optical density values of the pixels in the opacity $(C)$ :

$$
\text { Net integral of cataract density }(I D)=\sum_{[i, j] \in C} O D[i, j]
$$

Analysis was restricted to the opacity located within the central $7 \mathrm{~mm}$ diameter circular area of the pupillary aperture. This size was chosen because a previous study (unpublished observations) had shown that 95\% (245) of 258 retroillumination photographs had dilated pupils of at least $7 \mathrm{~mm}$ in diameter.

\section{Reproducibility Testing}

Seventeen individuals ranging in age from 18 to 79 years were recruited from the population of cataract patients

Table II. Components of measurement error in assessing the size of a posterior subcapsular cataract using the NEI retroillumination image analysis system

\begin{tabular}{lrrrrr}
\hline & \multicolumn{2}{c}{ Area $^{\mathrm{a}}$} & & \multicolumn{2}{c}{$\begin{array}{c}\text { Net integral of } \\
\text { density }\end{array}$} \\
\cline { 2 - 3 } \cline { 5 - 6 } Sources of variance & $\log _{\mathrm{e}}$ units & $\%$ & $\log _{\mathrm{e}}$ units & $\%$ \\
\hline Measurement error & 0.01361 & 100 & 0.00684 & 100 \\
1. Variability in photographers & 0.00021 & 2 & 0.00069 & 10 \\
$\quad$ Photographer & 0.00003 & & 0.00000 & \\
$\quad$ Eye $\times$ Photographer & 0.00018 & & 0.00069 & \\
2. Image & 0.00018 & 1 & 0.00303 & 44 \\
3. Variability in image analysis & 0.01322 & 97 & 0.00312 & 46 \\
Image analysis & 0.01031 & & 0.00158 & \\
Image $\times$ image analysis & 0.00291 & & 0.00154 & \\
4. Photographer $\times$ image analysis & 0.00000 & 0 & 0.00000 & 0 \\
\hline
\end{tabular}

ariginally measured in square millimetres.

${ }^{b}$ Originally measured in total OD of capacity. participating in a NEI-Intramural Research Board approved cataract protocol. Only those with cataract containing posterior subcapsular opacities and no cortical opacities were included in the study. The tenets of the Helsinki Declaration on Human Subjects were closely adhered to and informed consent was obtained after the nature of the study was explained.

Twenty eyes with posterior subcapsular opacities ranging in size from LOCS II $^{16}$ grades 1 to 4 were entered into the study. (Eleven eyes had grade 1, six eyes had grade 2, two eyes had grade 3 , and one eye had grade 4 posterior subcapsular opacity.) After maximal pupillary dilatation with $1 \%$ tropicamide and $2.5 \%$ phenylephrine hydrochloride ophthalmic solution, images of the posterior subcapsular opacities were acquired with the Oxford retroillumination CCD camera system. The image of each eye was acquired twice by each of the two photographers (M.L.L. and M.S.L.). Before every session, the regimen of patient positioning, camera realignment and focusing was repeated by each photographer. A total of 80 images was obtained - four sets of images for each eye. Several days to weeks after the images were taken the analysis of the

Table III. Components of total variability in assessing the size of a posterior subcapsular cataract using the NEI retroillumination image analysis system

\begin{tabular}{lrrrrrr}
\hline & \multicolumn{3}{c}{ Area $^{\mathrm{a}}$} & & \multicolumn{2}{c}{$\begin{array}{c}\text { Net integral of } \\
\text { density }\end{array}$} \\
\cline { 2 - 3 } \cline { 5 - 6 } Components of total variability & $\log _{\mathrm{e}}$ units & $\%$ & & $\log _{\mathrm{e}}$ units & $\%$ \\
\hline Eye & 3.34456 & 99.6 & & 5.06149 & 99.9 \\
Measurement error & 0.01361 & 0.4 & 0.00684 & 0.1 \\
\hline
\end{tabular}

"Originally measured in square millimetres.

${ }^{\mathrm{b}}$ Originally measured in total OD of capacity. 
Table IVA. 95\% prediction interval for true area of a posterior subcapsular cataract

\begin{tabular}{lcc}
\hline True area $\left(\mathrm{mm}^{2}\right)$ & Current data $\left(\mathrm{mm}^{2}\right)$ & $\begin{array}{c}\text { Data from } \\
\text { Datiles } \text { et al. }{ }^{11}\left(\mathrm{~mm}^{2}\right)\end{array}$ \\
\hline 0.10 & $(0.08,0.13)$ & $(0.01,0.29)$ \\
3.0 & $(2.4,3.8)$ & $(2.3,3.8)$ \\
5.0 & $(4.0,6.3)$ & $(4.1,6.0)$ \\
10 & $(7.9,13)$ & $(8.7,11)$ \\
20 & $(16,25)$ & $(18,22)$ \\
\hline
\end{tabular}

acquired images was performed by one of the investigators (M.L.L.) using the NEI-designed image analysis software. The images were analysed twice with an interval of several days to 2 weeks betweeen the two analysis sessions. In every case, the analyser was unaware of the results of any previously performed analysis.

\section{Statistical Analysis}

Preliminary analyses indicated that the variability of cataract area and net integral of the density increased with increasing values of these measures. ${ }^{17-19}$ Logarithmic transformation of the measurements yielded more homogeneous variance estimates and was thus used in all subsequent analyses. A crossed and nested design with all factors assumed to be random was used. This design permitted the evaluation of the four factors contributing to the variability in the measurements: eyes, photographers, images and image analysis. The linear model is given by:

$$
y_{i j k l}=\mu+\alpha_{i}+\beta_{j}+\alpha \beta_{i j}+\gamma_{k(i j)}+\delta_{l(i)}+\beta \delta_{j l(i)}+\gamma \delta_{k(i j)(i)}
$$

where $\mu$ is the overall mean (on the logarithmic scale); $\alpha_{i}$ is the effect for eye $i ; \beta_{j}$ is the effect for photographer $j ; \gamma_{k(i j)}$ is the image effect, and $\delta_{l(i)}$ is the image analysis effect. $\alpha \beta_{i \text {, }}$ $\beta \delta_{j(i)}$ and $\gamma \delta_{k(i j)(i)}$ are the interactions. ${ }^{20}$ To derive the components of variance, the method of restricted maximum likelihood was used. ${ }^{21,22}$

\section{RESULTS}

The posterior subcapsular opacities varied in size, with area ranging from 0.02 to $20.14 \mathrm{~mm}^{2}$ (mean $2.926 \mathrm{~mm}^{2}$ ) and net integral of density ranging from 8.05 to 10082.53 (mean 94.197). Estimates of measurement error and its components for area and net integral density are shown in Table II. The analysis of variance and subsequent estimation of components of measurement error were based on the natural logarithms of the observations. For area, the largest component contributing to measurement error was the variability in image analysis (97\%). Only about $2 \%$ and $1 \%$ of the total measurement error were from variability in photographers and from variability in images, respectively. On the other hand, for net integral of density, most of the measurement error came almost equally from variability in images (44\%) and from variability in image analysis $(46 \%)$. Variability in photographers contributed $10 \%$ to the total measurement error. Analysis of variance showed that variability due to image analysis was significantly greater than zero for both area and net integral of density. Furthermore, variability due to images was sig-
Table IVB. $95 \%$ prediction interval for true net integral of density of a posterior subcapsular cataract

\begin{tabular}{lc}
\hline $\begin{array}{l}\text { True net integral of density } \\
\text { (total OD of opacity) }\end{array}$ & $\begin{array}{c}95 \% \text { prediction interval } \\
\text { (total OD of capacity }\end{array}$ \\
\hline 10 & $(8.5,12)$ \\
100 & $(85,118)$ \\
2000 & $(1690,2360)$ \\
5000 & $(4240,5900)$ \\
10000 & $(8500,11800)$ \\
\hline
\end{tabular}

nificant for net integral of density. As a percentage of total variability (Table III), i.e. the sum of measurement error and variability between eyes, measurement error for net integral of density $(0.1 \%)$ was somewhat smaller than measurement error for area $(0.4 \%)$.

\section{DISCUSSION}

The NEI retroillumination image analysis system was developed with the goal of further improving the computer planimetry system. " By using a CCD camera we shortened image acquisition time and eliminated the use of photographic film. We were able to gauge image quality at the time of image acquisition, do on-line image analysis and remove the potential for variations arising from the use and storage of film. We also made use of interactive analysis in order to analyse separately different types of cataracts and remove artefacts often found in retroillumination images. As this step cannot yet be automated, we allowed manual editing of the processed image.

At present, the standard quantity measured by other analysis systems is area or percentage area of cataract. From our experience with posterior subcapsular opacities we have found that this parameter does not correlate well with any subjective or objective tests of vision. Our current image analysis system provides the net integral of density measure as well as the area. Net integral of density, as computed, measures the total cataract concentration. Additional research is needed to evaluate the association of this measurement with changes in visual function.

Additional cataract indices, as measured by the system, are currently under study. They are the centrality of area and net integral of density, and centrality-weighted values of area and density. These new indices quantify cataract as to its location relative to the visual axis.

Repeatability of the new image analysis system was evaluated in the study. Measurement errors of two cataract indices (area and net integral of density) obtained were estimated and their importance assessed. Measurement error for an eye was estimated to be 0.0361 for $\log _{\mathrm{e}}$ (area), where area was measured in square millimetres. Datiles and co-workers, " in the application of the computer planimetry method to quantify posterior subcapsular cataracts from Neitz-Kawara retroillumination photographs, obtained a measurement error of 0.01264 for (area) $)^{1 / 2}$. To compare the measurement errors obtained on different scales in the two studies, $95 \%$ prediction intervals in original units were computed for the two data sets. For the new system, the $95 \%$ prediction interval on the logarithmic 
scale for true area $(a)$ is $\log _{a} \pm 1.96(0.01361)^{1 / 2}$. In original units $\left(\mathrm{mm}^{2}\right)$ this is $(a / 1.26,1.26 a)$. A similar interval for the previous system on the square root scale is $a^{1 / 1} \pm 1.96$ $(0.01264)^{1 / 2}$. These limits are then squared to obtain the interval on the original scale. Examples are shown in Table IVA. It can be seen from this table that the current data, compared with the data of Datiles and co-workers, yielded somewhat narrower intervals for small opacities and wider intervals for large opacities. Nevertheless, the intervals are of similar width. As a proportion of total variability, measurement error for area $(0.4 \%)$ based upon the current technique is smaller than that based upon the planimetry method $(1 \%)$. It can thus be concluded that the clinical usefulness of the methodology described by Datiles and co-workers" ${ }^{11}$ also applies to the current one.

For net integral of density, the $95 \%$ prediction intervals obtained followed a similar pattern to that for area (Table IVB) - the larger the true value of the density, the wider the prediction interval.

Sources of variability were also identified. For area, variability in image analysis was the largest contributor to measurement error. This was not surprising since, with almost all of the retroillumination images, the analyser had to edit the processed image manually for artefacts and non-cataractous age-related lens changes. Similarly, Datiles and co-workers" showed that most of the variability in the measurements obtained with the computer planimetry method was due to outlining and area assessment (the analogue to image analysis in the current technique). On the other hand, the major contributors to measurement error for net integral of density were the variability in image analysis and the variability in images. This latter effect was significant for density because images taken at different times show variability in the amount of light reflected off the retina and because the computer has some limitation as to how much light variation it can correct for. This was not a problem for area, as assessment by the analyser is not as vulnerable to variations in illumination. This variation is mainly caused by the methods of illumination, optics and video image acquisition. These observed variabilities are expected to decrease with improvement in the optics and electronics of the device.

In summary, this study describes the application of the recently designed NEI retroillumination image analysis system to the quantification of posterior subcapsular cataracts. This user-friendly semi-automated system combines speed, ease of operation and interactive analysis. Evaluation of the system for cataract area indicates a level of reproducibility comparable to that of the computer planimetry method.

Key words: Cataract quantification, Image analysis, Posterior subcapsular cataract, Reproducibility, Retroillumination.

\section{REFERENCES}

1. Fincham EF. Photographic recording of opacities of the ocular media. Br J Ophthalmol 1955;39:85-9.
2. Kawara T, Obazawa H. A new method of retroillumination photography of cataractous lens opacities. Am J Ophthalmol 1980;90:186-9.

3. Brown NAP, Dawson T. A new British ophthalmic camera. Br J Photog 1987;134:1253-4.

4. Sparrow JM, Brown NAP, Shun-Shin GA, Bron AJ. The Oxford modular cataract image analysis system. Eye 1990;4:638-48.

5. Brown NAP, Bron AJ, Sparrow JM. Methods for evaluation of lens changes. Int Ophthalmol 1988;12:229-35.

6. Kawara T, Obazawa H, Nakano R, Sasaki M, Sakata T. Quantitative evaluation of cataractous lens opacities with retroillumination photography. Jpn J Clin Ophthalmol (Rinsho Ganka) 1979;33:21-6.

7. Wolfe JK, Chylack LT Jr. Objective measurement of cortical and subcapsular opacification in retroillumination photographs. Ophthalmic Res 1990;22(Suppl 1):62-7.

8. Miyauchi A, Mukai S, Sakamoto Y. A new analysis method for cataractous images taken by retroillumination photography. Ophthalmic Res 1990;22(Suppl 1):74-7.

9. Khu PM, Kashiwagi T. Subjective (LOCS II) versus objective (BGS) measures of cortical and subcapsular cataracts in retroillumination photographs. Ophthalmic Res 1990; 22(Suppl 1):68-70.

10. Sasaki K, Sakamoto Y, Shibata T, Emori Y. The multipurpose camera: a new anterior eye segment analysis system. Ophthalmic Res 1990;22(Suppl 1):3-8.

11. Datiles MB III, Podgor MJ, Sperduto RD, Kashima K, Edwards P, Hiller R. Measurement error in assessing the size of posterior subcapsular cataracts from retroillumination photographs. Invest Ophthalmol Vis Sci 1989;30: 1848-54.

12. Harris ML, Hanna KJ, Shun-Shin GA, Holden R, Brown NAP. Analysis of retroillumination photographs for use in longitudinal studies of cataract. Eye 1993;7:572-7.

13. Vivino MA, Mahurkar A, Trus B, Lopez L, Datiles M. Quantitative analysis of retroillumination images. Invest Ophthalmol Vis Sci (ARVO Abstr) 1994;35:1947.

14. Rasband W. NIH image 1.53. NTIS accession no. PB90500687. Available from: National Technical Information Service, 5285 Port Royal Road, Springfield, VA 22161, USA.

15. Sternberg S. Biomedical image processing. IEEE Computer 1983;16:22-34.

16. Chylack LT Jr, Leske MC, McCarthy D, Khu PM, Kashiwagi T, Sperduto RD. Lens opacities classification system II (LOCS II). Arch Ophthalmol 1989;107:991-7.

17. Altman DG, Bland JM. Measurement in medicine: the analysis of method comparison studies. Statistician 1983;32:307-17.

18. Bland JM, Altman DG. Statistical methods for assessing agreement between two methods of clinical measurement. Lancet 1986;1:307-10.

19. Dixon WJ, editor. BMDP statistical software manual. Berkeley: University of California Press, 1992.

20. Landis JR, Koch GG. A review of statistical methods in the analysis of data arising from observer reliability studies: I. Stat Neerland 1975;29:101-23.

21. SAS Institute Inc. SAS/STAT user's guide. Version 6. 4th ed. Vol 2. Cary, NC: SAS Institute, 1989.

22. Searle SR, Casella G, McCulloch CE. Variance components. New York: Wiley, 1992. 